Review Article Journal of Epilepsy Research pISSN 2233-6249 / eISSN 2233-6257

Received August 20, 2017 Accepted October 30, 2017

Corresponding author: Ji Hyun Kim Department of Neurology, Korea University Guro Hospital, Korea University College of Medicine, 148 Guro-dong ro, Guro-gu, Seoul 08308, Korea

Tel. +82-2-2626-3171

Fax. +82-2-2626-1256

E-mail; jhkim.merrf@gmail.com

\title{
Grey and White Matter Alterations in Juvenile Myoclonic Epilepsy: A Comprehensive Review
}

\author{
Ji Hyun Kim \\ Department of Neurology, Korea University Guro Hospital, Korea University College of Medicine, Seoul, Korea
}

\begin{abstract}
Juvenile myoclonic epilepsy (JME) has been classified as a syndrome of idiopathic generalized epilepsy and is characterized by a strong genetic basis, age-specific onset of seizures, specific types of seizures, generalized spike-wave discharges on electroencephalography, and a lack of focal abnormality on magnetic resonance imaging (MRI). Recently, a wide range of advanced neuroimaging techniques have been utilized to elucidate the neuroanatomical substrates and pathophysiological mechanisms underlying JME. Specifically, a number of quantitative MRI studies have reported focal or regional abnormalities of the subcortical and cortical grey matter, particularly the thalamus and frontal cortex, in JME patients. In addition, diffusion tensor imaging studies have pointed to disrupted microstructural integrity of the corpus callosum and multiple frontal white matter tracts as well as thalamofrontal dysconnectivity in JME patients. Converging evidence from neuroimaging studies strongly suggests that JME is a predominantly thalamofrontal network epilepsy, challenging the traditional concept of JME as a generalized epilepsy. There is also limited evidence indicating extrafrontal and extrathalamic involvement in JME. This systematic review outlines the main findings from currently available MRI studies focusing on grey and white matter alterations, and discusses their contributions to the etiology and pathophysiology of JME. The clinical utility, advantages, and drawbacks of each imaging modality are briefly described as well. (2017;7:77-88)
\end{abstract}

Key words: Juvenile myoclonic epilepsy, Voxel-based morphometry, Surface-based morphometry, Diffusion tensor imaging, Thalamus, Frontal lobe

\section{Introduction}

Juvenile myoclonic epilepsy (JME) is a well-defined and common syndrome of idiopathic generalized epilepsy (IGE), accounting for approximately $4-10 \%$ of all epilepsies with a high genetic predisposition. It is clinically characterized by myoclonic jerks of the upper extremities on awakening, generalized tonic-clonic seizures, and less frequently by absence seizures. Disease onset peaks between the ages of 14 and 16 years, with a range of 8-26 years. Seizures commonly follow a circadian rhythm with preponderance upon awakening, and may be precipitated by a variety of stimuli such as sleep deprivation, fatigue, alcohol intake, stress, or complex cognitive tasks. Typical interictal electroencephalography (EEG) features of JME consist of 3-6 Hz generalized spike-wave or polyspike-wave discharges on a normal background, predominantly with frontocentral accentuation.

Although the neuroanatomical basis underlying JME remains elu- sive, cumulative evidence from experimental studies have suggested that the thalamus, along with an aberrant thalamocortical circuit, plays a pivotal role in the generation of generalized spike-wave discharges, which is considered to be a fundamental pathophysiology of JME. ${ }^{2}$ Visual assessment of clinical magnetic resonance imaging (MRI) is, by definition, normal in JME patients. ${ }^{3}$ However, recent advances in computational analysis of structural MRI have contributed greatly to the understanding of structural alterations in JME patients. ${ }^{4,5} \mathrm{~A}$ number of quantitative MRI studies have revealed grey matter abnormalities of the thalamus and cortex-especially the frontal cortex-in JME patients when compared to healthy controls, although there is some debate across studies as to whether the cortical abnormality is associated with an increase or decrease in volume. ${ }^{4 \cdot 6}$ Recent studies using diffusion tensor imaging (DTI), an MRI method that is sensitive to white matter (WM) architecture, ${ }^{7}$ have also disclosed alterations in the microstructural integrity of the thalamocortical network in JME patients. ${ }^{8-11}$ This review aims to comprehensively 
reflect upon the available evidence on cortical and subcortical grey matter (GM) alterations as well as WM abnormalities, and their potential contributions to the pathophysiology of JME.

\section{Cortical grey matter volume changes: voxel-based morphometry}

Voxel-based morphometry (VBM), one of the most widely used structural MRI analytic methods, is a fully automated, unbiased, operator-independent technique that detects regionally specific differences in GM volume or concentration on a whole-brain voxel-wise comparison between groups of subjects. ${ }^{12}$ There are 12 VBM studies on JME available to date (Table 1). ${ }^{13-24}$ A pioneering study using an incipient model of VBM demonstrated an increase in mesiofrontal GM in JME patients relative to matched controls, suggesting the possibility that JME patients may have structural abnormalities of the frontal lobe. ${ }^{13}$ Subsequent studies investigating the same paradigm using more advanced VBM replicated the finding of increased GM concentration or volume in the frontal cortex, especially in the mesiofrontal region, further supporting the premise of structural alteration of the frontal cortex in JME. ${ }^{14,16,17,19}$
It is, however, largely unknown whether the observed frontal GM abnormalities are a reflection of histopathological changes. A few postmortem studies have shown cortical dystopic neurons, other microscopic structural abnormalities (so-called 'microdysgenesis'), and increased neuronal density in the frontal cortex in a small number of IGE (including JME) patients. ${ }^{25,26}$ Histological abnormalities such as microdysgenesis could lead to an increase in the volume of the GM ribbon, which may explain the morphological changes of the frontal cortex observed in VBM results. ${ }^{13}$ However, Lyon and Gastaut expressed some doubts with regard to the postmortem finding of microdysgenesis in IGE since such abnormalities could also be seen in neurologically normal controls. ${ }^{27}$ In addition, a controlled, blinded histological study did not replicate the findings of microdysgenesis and increased frontal neuronal density in IGE. ${ }^{28}$ Although frontal GM abnormalities found in VBM studies may not be firmly supported by the histopathological studies, a growing body of evidence from recent functional neuroimaging studies provides a robust basis for the hypothesis of frontal dysfunction in the pathogenesis of JME. Specifically, a positron emission tomography study using fluorodeoxyglucose showed a reduction in metabolism of the prefrontal and premotor cortex in JME patients. ${ }^{29}$ MR spectroscopy studies have re-

Table 1. Voxel-based morphometry studies in juvenile myoclonic epilepsy

\begin{tabular}{|c|c|c|c|c|}
\hline Study & Cohort & MRI scanner & Analytic tool & Key findings in JME patients versus controls \\
\hline Woermann et al. ${ }^{13}$ & 20 JME vs. 30 controls & $1.5 \mathrm{~T}(\mathrm{GE})$ & SPM96 & Increased GM concentration in mesiofrontal region \\
\hline Betting et al. ${ }^{14}$ & 44 JME vs. 47 controls & 2.0T (Elscint) & SPM2 & $\begin{array}{l}\text { Increased GM concentration in frontobasal and superior } \\
\text { mesiofrontal regions }\end{array}$ \\
\hline Tae et al. ${ }^{15}$ & 19 JME vs. 19 controls & $1.5 \mathrm{~T}(\mathrm{GE})$ & SPM2 & Decreased GM concentration in prefrontal lobe \\
\hline Kim et al. ${ }^{16}$ & 25 JME vs. 44 controls & 1.5T (Siemens) & SPM2 & $\begin{array}{l}\text { Increased GM volume in superior mesiofrontal regions } \\
\text { and reduced thalamic GM volume }\end{array}$ \\
\hline Lin et al. ${ }^{17}$ & 60 JME vs. 30 controls & 1.5T (Siemens) & SPM5 & $\begin{array}{l}\text { Increased GM volume in superior frontal, orbitofrontal, } \\
\text { medial frontal regions and reduced GM volume in } \\
\text { thalamus, insula, cerebellum }\end{array}$ \\
\hline Roebling et al. ${ }^{18}$ & 19 JME vs. 20 controls & 1.5T (Siemens) & SPM2 & No difference in cortical or subcortical GM volume \\
\hline $\begin{array}{l}\text { de Araújo Filho } \\
\text { et al. }{ }^{19}\end{array}$ & 54 JME vs. 30 controls & 1.5T (Siemens) & SPM5 & $\begin{array}{l}\text { Increased GM volume in superior frontal, medial frontal } \\
\text { regions and reduced GM volume in thalamus, insula, } \\
\text { cerebellum }\end{array}$ \\
\hline Mory et al. ${ }^{20}$ & 21 JME vs. 20 controls & 2.0T (GE) & SPM5 & Reduced GM volume in anterior thalamus \\
\hline $\begin{array}{l}\text { O'Muircheartaigh } \\
\text { et al. }{ }^{21}\end{array}$ & 28 JME vs. 55 controls & 3.0T (GE) & SPM8 & $\begin{array}{l}\text { Reduced GM volume in supplementary motor area and } \\
\text { posterior cingulate cortex }\end{array}$ \\
\hline Liu et al. ${ }^{22}$ & 15 JME vs. 25 controls & 1.5T (Siemens) & SPM8 & $\begin{array}{l}\text { Reduced GM volume in precentral, middle frontal, } \\
\text { temporal, superior parietal regions }\end{array}$ \\
\hline Kim et al. ${ }^{23}$ & 33 JME vs. 50 controls & 3.0T (Siemens) & SPM8 & Reduced GM volume in anterior thalamus \\
\hline Swartz et al. ${ }^{24}$ & $17 \mathrm{JME}$ vs. 17 controls & 1.5T (Philips) & SPM5 & No difference in cortical or subcortical GM volume \\
\hline
\end{tabular}


peatedly demonstrated metabolic dysfunctions of the frontal cortex, particularly in the prefrontal region. ${ }^{30-34}$ Resting-state functional MRI studies have also shown a reduction in functional connectivity in the prefrontal and premotor cortex in JME patients. ${ }^{35,36}$ Moreover, a number of neurocognitive studies have pointed to frontal cognitive dysfunctions in JME patients, ${ }^{37-39}$ in line with functional abnormalities of the frontal lobe revealed by functional neuroimaging studies. ${ }^{10,40-42}$ Taken together, ample evidence indicates a coincidence of frontal cognitive impairment and structural and functional abnormalities of the frontal lobe in JME.

The finding of increased frontal GM volume has not been replicated in other studies: three studies found a reduction in GM volume or concentration in the prefrontal cortex, precentral cortex, or supplementary motor area, 15,21,22 whereas two studies failed to disclose any differences in frontal GM volume between patients and controls. ${ }^{18,24}$ These inconsistencies across the studies could not be properly accounted for but might, in part, be attributed to several factors, including differences in magnetic field strength, VBM methodology, sample size of the cohort, and genetic heterogeneity. Another major reason for the discrepancy may lie in the use of different statistical methods and thresholds for multiple comparison correction employed in each VBM study (i.e., false discovery rate correction vs. familywise error correction and voxel-level inference vs. cluster-level inference vs. small volume correction). ${ }^{43}$ The VBM results could also be particularly affected by the sample size of the control group and selection of nuisance covariates such as total intracranial volume, age, or gender. ${ }^{44-46}$ Moreover, reporting bias in the literature due to selective analysis, and a trend of publication of only positive results should also be taken into consideration when interpreting and comparing the results of VBM studies. This bias is well documented in the studies on brain volume abnormalities in psychiatric disorders. ${ }^{47}$ Therefore, in order to overcome these shortcomings of VBM and to clearly determine whether JME is associated with structural abnormality of the frontal cortex, future studies should employ a larger sample size, selection of genetically homogenous patients, high magnetic field strength scanners, most updated VBM methods, rigorous statistical thresholds for multiple comparison correction, and inclusion of nuisance covariates that potentially affect the results.

A newly developed statistical technique, named signed differential mapping (http://www.sdmproject.com), has been increasingly used in the meta-analysis of neuroimaging studies, and its usefulness has been demonstrated on various neurological and psychiatric disorders such as Parkinson's disease, amyotrophic lateral sclerosis, schizophrenia, and obsessive-compulsive disorder. ${ }^{48} \mathrm{~A}$ recent study using this meta-analytic method of 7 published VBM studies with a total of 211 JME patients and 241 healthy controls $13,14,16-18,21,22$ revealed increased GM volume in the bilateral medial frontal gyrus and anterior cingulate cortex, and reduced GM volume in the bilateral thalamus in JME patients, supporting the notion of structural abnormality of the thalamofrontal circuitry in the pathogenesis underlying JME. ${ }^{49}$ Another meta-analysis study using 7 VBM studies (which included studies not specified in the article) also found increased GM volume in the mesiofrontal region and reduced GM volume in the bilateral perisylvian regions in a JME cohort. ${ }^{6}$

\section{Cortical grey matter morphological changes: surface-based morphometry}

An alternative approach to the quantification of morphometric GM changes is surface-based morphometry, a well-validated analytic procedure $^{50,51}$ that measures cortical thickness, surface area, and folding curvature in addition to cortical volume. It provides complementary information to VBM for understanding the neuroanatomy of various brain disorders by allowing the regional distribution and quantification of cortical GM changes to be specifically examined in contrast to VBM, which often combines GM and WM within regional volumes. ${ }^{50}$ Although VBM does permit precise assessment of GM volumetric changes, it is limited by the fact that it provides a mixed measurement of GM, including surface area, cortical folding, and cortical thickness. Furthermore, VBM is considered to be less robust to noise and mis-segmentation, less accurate due to the limited resolution of the voxel grid, and affected by partial volume effects at the boundaries of highly convoluted structures, such as deep sulci. ${ }^{52}$ In contrast, surface-based morphometry allows a more direct index of cortical morphology that is less susceptible to positional variance given that the extraction of the cortex follows the GM surface despite local variations in its position, enabling a more sensitive measurement of cortical morphological changes. ${ }^{53}$

There are six published studies in the English literature that investigated cortical thickness alterations in this patient population (Table 2). ${ }^{54-59}$ Similar to those of VBM studies, the results showed considerable variance across the studies with regard to which cortical structures were affected and whether cortical GM alteration was related to an increase or a reduction in cortical thickness. The first study, by Tae et al.. ${ }^{54}$ reported a significant cortical thinning in bilateral superi- 
Table 2. Surface-based morphometry studies in juvenile myoclonic epilepsy

\begin{tabular}{|c|c|c|c|c|}
\hline Study & Cohort & MRI scanner & Analytic tool & Key findings in JME patients versus controls \\
\hline Tae et al. $^{54}$ & $\begin{array}{l}19 \text { JME vs. } 18 \\
\text { controls }\end{array}$ & 1.5T (GE) & CIVET & $\begin{array}{l}\text { Cortical thinning in bilateral superior, middle, medial frontal } \\
\text { gyri, and superior, middle, inferior temporal gyri }\end{array}$ \\
\hline Ronan et al. ${ }^{55}$ & $\begin{array}{l}24 \text { JME vs. } 40 \\
\text { controls }\end{array}$ & $1.5 \mathrm{~T}(\mathrm{GE})$ & FreeSurfer 4.1 & $\begin{array}{l}\text { No difference in cortical thickness } \\
\text { Reduced surface area in middle temporal gyrus, anterior } \\
\text { cingulate gyrus, and increased surface area in occipital pole, } \\
\text { fusiform gyrus, and precuneus } \\
\text { Reduced mean curvature in bilateral insular cortex }\end{array}$ \\
\hline Alhusaini et al. $^{56}$ & $\begin{array}{l}24 \text { JME vs. } 40 \\
\text { controls }\end{array}$ & $1.5 \mathrm{~T}(\mathrm{GE})$ & FreeSurfer 4.5 & $\begin{array}{l}\text { Cortical thickening in bilateral orbitofrontal cortex, } \\
\text { mesiofrontal cortex, right precuneus, inferior parietal cortex, } \\
\text { and left temporal cortex }\end{array}$ \\
\hline Lin et al. $^{57}$ & $\begin{array}{l}19 \text { JME vs. } 57 \\
\text { controls }\end{array}$ & $1.5 \mathrm{~T}(\mathrm{GE})$ & FreeSurfer 5.1 & $\begin{array}{l}\text { Prospectively increased cortical volume in bilateral } \\
\text { frontoparietal and posterior temporal cortex } \\
\text { Prospectively increased cortical thickness in bilateral } \\
\text { frontoparietal and posterior temporal cortex } \\
\text { Prospectively increased surface area in right superior parietal } \\
\text { and inferior frontal cortex }\end{array}$ \\
\hline Kim et al. ${ }^{58}$ & $\begin{array}{l}18 \text { JME vs. } 22 \\
\text { controls }\end{array}$ & $1.5 T(G E)$ & CIVET & $\begin{array}{l}\text { Cortical thinning in left dorsolateral frontal, lateral temporal, } \\
\text { medial occipital cortex, and right paracentral lobule, } \\
\text { precuneus, dorsolateral parietal cortex, inferior temporal } \\
\text { cortex }\end{array}$ \\
\hline Park et al. ${ }^{59}$ & $\begin{array}{l}21 \text { JME vs. } 13 \\
\text { controls }\end{array}$ & 3.0T (Philips) & FreeSurfer 5.1 & $\begin{array}{l}\text { Cortical thinning in right postcentral, lingual, orbitofrontal, } \\
\text { lateral occipital, and inferior temporal cortex }\end{array}$ \\
\hline
\end{tabular}

MRI, magnetic resonance imaging; JME, juvenile myoclonic epilepsy; GE, general electric.

or, middle, and medial frontal gyri, and the superior, middle, inferior temporal gyri in patients, suggesting an involvement of the temporal cortex beyond the frontal cortex in the neuroanatomical changes underlying JME. Other studies also found widespread cortical thinning in the frontal, temporal, parietal, and occipital gyri, suggesting that not only the frontal cortex but also the extrafrontal cortex could be affected in JME. ${ }^{58,59}$ On the other hand, Ronan et al. ${ }^{55}$ found reduced surface area in the middle temporal gyrus and anterior cingulate gyrus, increased surface area in the occipital pole, fusiform gyrus, and precuneus, and reduced mean curvature in bilateral insular cortices in 24 JME patients compared to 40 healthy controls. Another study performed by the same group revealed multiple regions of cortical thickening in bilateral orbitofrontal cortices, mesiofrontal cortex, right precuneus, inferior parietal cortex, and left temporal cortex ${ }^{56}$ which seems contradictory to those of former studies exhibiting widespread cortical thinning in the patient group. ${ }^{54,58,59}$ As with the VBM findings, this inconsistency between the studies could be ascribed to several factors including differences in the algorithm for surface-based morphometry, sample size of the cohort, and statistical methods. A more recent, well-designed longitudinal study investigated prospective changes in cortical morphometry in new-onset JME patients versus controls. ${ }^{57}$ Patients had greater cortical volume and greater cortical thickness in the bilateral frontoparietal and posterior temporal regions over the first two years following the diagnosis as compared to typically developing children. The results clearly demonstrated attenuation of the age-related decline in cortical volume and thickness of the higher-association frontoparietotemporal regions, indicating abnormal structural brain development in JME. ${ }^{57}$ While the majority of the VBM studies found cortical GM volume changes mainly localized to the frontal lobe, surface-based morphometry studies showed cortical thickness changes in the extrafrontal cortex in addition to the frontal cortex, suggesting that surface-based morphometry might be more sensitive to VBM in detecting cortical morphological changes in JME.

\section{Subcortical grey matter changes}

A growing body of evidence indicates that alterations of the thalamus and thalamocortical network play a key role in the pathophysiology of JME. A number of quantitative MRI studies have attempted to explore structural changes of the thalamus in JME. Studies using manual volumetry or automated segmentation methods have repeatedly reported a decrease in whole thalamic volume in patients relative to controls, implicating a specific macrostructural alteration 
of the thalamus in JME (Table 3). 23,40,56,58,60-62 This finding could be supported by multiple lines of evidence from a variety of neuroimaging studies demonstrating functional abnormalities of the thala- mus in JME. These abnormalities included thalamic metabolic dysfunction, $32,33,63,64$ increased thalamic blood oxygenation level-dependent activity in relation to generalized spike-wave discharges, ${ }^{65-67}$

Table 3. Subcortical grey matter morphological changes in juvenile myoclonic epilepsy

\begin{tabular}{|c|c|c|c|c|}
\hline Study & Cohort & MRI scanner & Analytic tool & Key findings in JME patients versus controls \\
\hline Pulsipher et al. ${ }^{40}$ & $\begin{array}{l}20 \text { JME vs. } 51 \\
\text { controls }\end{array}$ & $1.5 \mathrm{~T}(\mathrm{GE})$ & BRAINS2 & Reduced volume of right whole thalamus \\
\hline \multirow[t]{2}{*}{ Kim et al. ${ }^{23}$} & \multirow[t]{2}{*}{$\begin{array}{l}33 \text { JME vs. } 50 \\
\text { controls }\end{array}$} & \multirow[t]{2}{*}{ 3.0T (Siemens) } & FSL-FIRST & $\begin{array}{l}\text { Reduced volume of bilateral whole thalamus } \\
\text { Regional atrophy in anteromedial and posterodorsal inferior } \\
\text { thalamus }\end{array}$ \\
\hline & & & VBM & Bilateral anteromedial thalamic atrophy \\
\hline Keller et al. ${ }^{60}$ & $\begin{array}{l}10 \text { JME vs. } 62 \\
\text { controls }\end{array}$ & 3.0T (Philips) & $\begin{array}{l}\text { Manual volumetry, } \\
\text { FreeSurfer }\end{array}$ & Reduced volume of bilateral whole thalamus \\
\hline Alhusaini et al. ${ }^{56}$ & $\begin{array}{l}24 \text { JME vs. } 40 \\
\text { controls }\end{array}$ & $1.5 \mathrm{~T}(\mathrm{GE})$ & FreeSurfer 4.5 & Reduced volume of bilateral whole thalamus \\
\hline \multirow[t]{2}{*}{ Saini et al. ${ }^{61}$} & \multirow[t]{2}{*}{$\begin{array}{l}40 \text { JME vs. } 19 \\
\text { controls }\end{array}$} & \multirow[t]{2}{*}{ 3.0T (Philips) } & FSL-FIRST & $\begin{array}{l}\text { Reduced volume of bilateral whole thalamus } \\
\text { Regional atrophy in anteromedial and lateral thalamus } \\
\text { Bilateral anteromedial thalamic atrophy }\end{array}$ \\
\hline & & & VBM & \\
\hline Kim et al. ${ }^{58}$ & $\begin{array}{l}18 \text { JME vs. } 22 \\
\text { controls }\end{array}$ & $1.5 \mathrm{~T}(\mathrm{GE})$ & Manual volumetry & Reduced volume of bilateral whole thalamus and hippocampus \\
\hline \multirow[t]{2}{*}{ Mory et al. $^{20}$} & \multirow[t]{2}{*}{$\begin{array}{l}21 \text { JME vs. } 20 \\
\text { controls }\end{array}$} & \multirow[t]{2}{*}{ 2.0T (GE) } & VBM & $\begin{array}{l}\text { No difference in whole thalamic volume } \\
\text { Reduced GM volume in anterior thalamus }\end{array}$ \\
\hline & & & SPHARM & Regional atrophy in anterior and inferior thalamus \\
\hline Park et al. ${ }^{59}$ & $\begin{array}{l}21 \mathrm{JME} \text { vs. } 13 \\
\text { controls }\end{array}$ & 3.0T (Philips) & FreeSurfer 5.1 & No difference in whole thalamic volume \\
\hline Swartz et al. ${ }^{24}$ & $\begin{array}{l}17 \text { JME vs. } 17 \\
\text { controls }\end{array}$ & 1.5T (Philips) & Manual volumetry & Increased volume of bilateral whole thalamus \\
\hline Kim et al. ${ }^{16}$ & $\begin{array}{l}25 \text { JME vs. } 44 \\
\text { controls }\end{array}$ & 1.5T (Siemens) & VBM & Reduced GM volume in bilateral ventral lateral thalamus \\
\hline Lin et al. $^{17}$ & $\begin{array}{l}60 \text { JME vs. } 30 \\
\text { controls }\end{array}$ & 1.5T (Siemens) & VBM & Reduced GM volume in bilateral mediodorsal thalamus \\
\hline $\begin{array}{l}\text { de Araújo Filho } \\
\text { et al. }{ }^{19}\end{array}$ & $\begin{array}{l}54 \text { JME vs. } 30 \\
\text { controls }\end{array}$ & 1.5T (Siemens) & VBM & Reduced GM volume in bilateral pulvinar thalamus \\
\hline Helms et al. ${ }^{62}$ & $\begin{array}{l}23 \text { JME vs. } 38 \\
\text { controls }\end{array}$ & $1.5 \mathrm{~T}(\mathrm{GE})$ & $\begin{array}{l}\text { Manual volumetry } \\
\text { VBM }\end{array}$ & $\begin{array}{l}\text { Reduced volume of bilateral whole thalamus } \\
\text { Bilateral anteromedial thalamic atrophy }\end{array}$ \\
\hline Roebling et al. ${ }^{18}$ & $\begin{array}{l}19 \text { JME vs. } 20 \\
\text { controls }\end{array}$ & 1.5T (Siemens) & SPM2 & No difference in cortical or subcortical GM volume \\
\hline Keller et al. ${ }^{9}$ & $\begin{array}{l}10 \text { JME vs. } 59 \\
\text { controls }\end{array}$ & 3.0T (Philips) & Manual volumetry & Reduced volume of bilateral whole putamen \\
\hline Ciumas et al. ${ }^{79}$ & $\begin{array}{l}12 \text { JME vs. } 12 \\
\text { controls }\end{array}$ & $1.5 \mathrm{~T}(\mathrm{GE})$ & Manual volumetry & Reduced volume of bilateral whole putamen \\
\hline Lin et al. ${ }^{89}$ & $\begin{array}{l}56 \text { JME vs. } 42 \\
\text { controls }\end{array}$ & 1.5T (Siemens) & Manual volumetry & Reduced volume of right whole hippocampus \\
\hline Tae et al. ${ }^{15}$ & $\begin{array}{l}19 \text { JME vs. } 19 \\
\text { controls }\end{array}$ & 1.5T (GE) & Manual volumetry & Reduced volume of left whole hippocampus \\
\hline
\end{tabular}


and thalamocortical functional dysconnectivity. ${ }^{36,41,68}$ However, the finding of thalamic volume reduction was not replicated in other studies: two studies using automated segmentation methods failed to find between-group differences in thalamic volume, ${ }_{1}^{20,59}$ and another study using manual delineation found an increase in thalamic volume in patients compared with controls. ${ }^{24}$ Several factors, such as operator-dependent bias in manual segmentation and overestimation or underestimation of GM around the thalamic border by automated segmentation, could explain the incongruences between the studies.

A potential advantage of VBM over manual or automated segmentation methods is that while the latter only provides the whole volume of a given structure, VBM allows for localization of volumetric alteration within a structure (e.g., thalamus). Whereas a few studies found no difference in thalamic volume, ${ }^{18,21}$ the majority of recent VBM studies have consistently shown regional volume reduction in the thalamus of JME patients. Of particular interest is that the atrophied regions within the thalamus are not unanimous across the studies and include the ventrolateral, ${ }^{16}$ mediodorsal, ${ }_{1}^{17}$ anterior, ${ }_{1}^{20}$ anteromedial, ${ }^{23,61,62}$ and pulvinar thalamus. ${ }^{19}$ The thalamic subregions of localized volume reduction seemed to specifically correspond to the anterior nucleus, ventral anterior nucleus, and mediodorsal nucleus, in accordance with the previous studies showing a preferential involvement of the anterior-medial thalamus in the pathogenesis of both experimental and human models of IGE. Available electrophysiological studies using relevant animal models of human IGE have shown a crucial role of the anterior nucleus ${ }^{69,70}$ and mediodorsal nucleus ${ }^{71}$ in the initiation and propagation of generalized seizures. Combined EEG-functional MRI studies have demonstrated an important implication of anterior or medial thalamic activation in the generation or maintenance of generalized spike-wave discharges in subjects with IGE. ${ }^{6,72-74}$ It is of note that the anteromedial thalamus, which includes the anterior nucleus, ventral anterior nucleus, and mediodorsal nucleus, has intense structural and functional connectivity with the cingulate, premotor, and prefrontal cortices, as is well-documented in DTI and resting-state functional connectivity MRI studies. ${ }^{75-77}$ Given the strong connection between the anteromedial thalamus and frontal lobe, the rather consistent finding of anteromedial thalamic volume reduction is in line with those of VBM or surface-based morphometry studies showing frontal cortical abnormalities, further implicating the anteromedial thalamus in the pathophysiological hypothesis of thalamofrontal network abnormality in JME.
Complementary to VBM, vertex-based shape analysis is another fully automated method that provides useful information about the location and pattern of morphological changes of the subcortical GM structures. ${ }^{78}$ In contrast to VBM, which depends on locally averaged GM segmentations and is, therefore, sensitive to the inaccuracy of tissue-type classification and arbitrary smoothing procedures, vertex-based shape analysis automatically segments each subcortical GM based on the shape and intensity variations of the respective structure. Since vertex analysis directly measures changes in geometry and does not require additional smoothing procedures, it might have the potential to more precisely detect regional alterations of the subcortical GM than VBM. Using this method, Mory et al. ${ }^{20}$ found regional atrophy confined to the anterior and inferior portions of the thalamus in JME patients. Another study also found regional atrophy predominantly located in the anterior-medial and lateral aspects of the bilateral thalami. ${ }^{61}$ In a recent study investigating the same paradigm, Kim et al. ${ }^{23}$ showed that patients had thalamic atrophy confined to the anterior-medial as well as posterior-dorsal aspects. Collectively, the main findings from the surface analysis studies agree with those of VBM studies, corroborating that the anteromedial thalamus is implicated in the pathophysiological concept of thalamofrontal network abnormality underlying JME.

The other subcortical GM structures have received less attention than the thalamus due to a robust finding of thalamic involvement in JME. A few MRI studies exhibited a reduction in putaminal volume in patients in comparison with healthy controls. ${ }^{9,79}$ A growing body of evidence suggests a possible role of the basal ganglia in the modulation of generalized spike-waves or seizures in IGE. ${ }^{80,81}$ Specifically, an electrophysiological study on an animal genetic model of absence epilepsy demonstrated aberrant electrical events in the striatal output neurons in the corticostriatal pathway during spontaneous generalized spike-waves, implicating the basal ganglia in the promotion or termination of absence seizures. ${ }^{82}$ Simultaneous EEG-functional MRI studies have revealed a reduction of blood oxygenation level-dependent activity in the basal ganglia in association with generalized spike-waves in IGE patients. ${ }^{74,83,84} \mathrm{~A}$ resting-state functional MRI study also found enhanced functional connectivity within the basal ganglia network in IGE patients compared with controls, pointing to a modulatory role of the basal ganglia in IGE. ${ }^{85}$ It is generally accepted that the striatum modulates the activity of the output nuclei of the basal ganglia, which tonically inhibit their target nuclei in the thalamus and brainstem. Reduced activity in these output nuclei may cause a disinhibition of the thalamocortical projections, leading to a 
subsequent enhancement in cortical excitability. ${ }^{86}$ It is therefore conceivable that functional impairment in the striatum (e.g., putamen) may exaggerate thalamocortical activation and result in the promotion of generalized spike-waves or seizures in IGE. In support of this premise, a recent positron emission tomography study demonstrated a reduction in dopamine receptor binding restricted to the bilateral posterior putamen in JME patients. ${ }^{87}$ Together, both structural and functional abnormalities of the putamen may also be involved in the pathophysiology of JME. Moreover, given the strong connections between the putamen and frontal lobe, concomitant structural and functional abnormalities of the putamen suggest preferential involvement of striato-thalamofrontal networks in JME, $32,34,74,79,88$ and could account for the frontal executive dysfunctions in this patient population.

Several lines of evidence suggest that the hippocampus is involved in the epileptogenic network in JME. Specifically, a limited number of MRI studies have shown hippocampal volume reduction ${ }^{15,58,89}$ and metabolic dysfunction ${ }^{90}$ in JME patients relative to controls. In an electrophysiological study using source analysis of dense array scalp EEG, epileptiform discharges were localized not only to the orbitofrontal/medial frontopolar cortex but also to the basal-medial temporal cortex. ${ }^{91}$ From the cognitive perspective, in addition to the well-demonstrated frontal executive dysfunctions, ${ }^{10,37,39,40}$ several neurocognitive studies have pointed to verbal and visual memory dysfunctions in this patient group. ${ }^{92,93}$ Given the close relationship between hippocampal atrophy and memory dysfunction, it is speculated that JME patients with memory dysfunctions may have a hippocampal volume reduction. ${ }^{89}$ However, such a finding of hippocampal volume reduction was not replicated in other studies. ${ }^{61}$ Future study using a large sample size, higher magnetic field strength, and comprehensive neuropsychological assessments should elucidate the macrostructural change of the hippocampus and its neurocognitive correlates in JME patients.

Table 4. White matter changes in juvenile myoclonic epilepsy

\begin{tabular}{|c|c|c|c|c|}
\hline Study & Cohort & MRI scanner & Analytic tool & Key findings in JME patients versus controls \\
\hline Deppe et al. $^{8}$ & $\begin{array}{l}10 \text { JME vs. } 67 \\
\text { controls }\end{array}$ & 3.0T (Philips) & SPM5 & $\begin{array}{l}\text { Reduced FA in WM regions associated with anterior thalamus and } \\
\text { prefrontal cortex }\end{array}$ \\
\hline Keller et al. ${ }^{9}$ & $\begin{array}{l}10 \text { JME vs. } 59 \\
\text { controls }\end{array}$ & 3.0T (Philips) & SPM5 & Reduced FA in thalamocortical and frontal WM \\
\hline Kim et al. ${ }^{10}$ & $\begin{array}{l}25 \text { JME vs. } 30 \\
\text { controls }\end{array}$ & 3.0T (Siemens) & TBSS & $\begin{array}{l}\text { Reduced FA and increased MD in bilateral anterior and superior } \\
\text { corona radiata, genu and body of corpus callosum, and multiple } \\
\text { frontal WM tracts }\end{array}$ \\
\hline $\begin{array}{l}\text { O'Muircheartaigh } \\
\text { et al. }{ }^{21}\end{array}$ & $\begin{array}{l}28 \text { JME vs. } 38 \\
\text { controls }\end{array}$ & 3.0T (GE) & TBSS & Reduced FA in body and splenium of corpus callosum \\
\hline Liu et al. ${ }^{22}$ & $\begin{array}{l}15 \text { JME vs. } 25 \\
\text { controls }\end{array}$ & 1.5T (Siemens) & ExploreDTI & $\begin{array}{l}\text { Reduced FA in fornix, corpus callosum, uncinate fasciculi, superior } \\
\text { longitudinal fasciculus, anterior limb of internal capsule, and } \\
\text { corticospinal tracts }\end{array}$ \\
\hline $\begin{array}{l}\text { O'Muircheartaigh } \\
\text { et al. }{ }^{41}\end{array}$ & $\begin{array}{l}28 \text { JME vs. } 38 \\
\text { controls }\end{array}$ & 3.0T (GE) & $\begin{array}{l}\text { Probabilistic } \\
\text { tractography }\end{array}$ & $\begin{array}{l}\text { Reduced structural connectivity between anterior thalamus and } \\
\text { SMA }\end{array}$ \\
\hline Kim et al. ${ }^{58}$ & $\begin{array}{l}18 \text { JME vs. } 22 \\
\text { controls }\end{array}$ & $1.5 \mathrm{~T}(\mathrm{GE})$ & TBSS & $\begin{array}{l}\text { Reduced FA in frontal WM, corpus callosum, centrum semiovale, } \\
\text { and increased MD in posterior frontoparietal WM, corpus } \\
\text { callosum, temporal WM }\end{array}$ \\
\hline Vulliemoz et al. ${ }^{97}$ & $\begin{array}{l}15 \text { JME vs. } 18 \\
\text { controls }\end{array}$ & 3.0T (GE) & $\begin{array}{l}\text { Probabilistic } \\
\text { tractography }\end{array}$ & Reduced FA and increased $\mathrm{MD}$ in $\mathrm{WM}$ tracts connected to SMA \\
\hline Focke et al..$^{98}$ & $\begin{array}{l}12 \text { JME vs. } 44 \\
\text { controls }\end{array}$ & 3.0T (Siemens) & TBSS & $\begin{array}{l}\text { Reduced FA in corpus callosum, corticospinal tract, superior } \\
\text { longitudinal fasciculus, multiple frontal WM tracts, and } \\
\text { increased MD in forceps minor, anterior thalamic radiation, } \\
\text { inferior frontooccipital fasciculus }\end{array}$ \\
\hline Ekmekci et al. ${ }^{99}$ & $\begin{array}{l}24 \text { JME vs. } 28 \\
\text { controls }\end{array}$ & 1.5T (Philips) & ROI approach & $\begin{array}{l}\text { Reduced FA and increased MD in dorsolateral prefrontal cortex, } \\
\text { SMA, thalamus, posterior cingulate cortex, corpus callosum, } \\
\text { corona radiata, and middle frontal WM }\end{array}$ \\
\hline
\end{tabular}

MRI, magnetic resonance imaging; JME, juvenile myoclonic epilepsy; SPM, statistical parametric mapping; FA, fractional anisotropy; WM, white matter; TBSS, tract-based spatial statistics; MD, mean diffusivity; GE, general electric; SMA, supplementary motor area; ROI, region of interest. 


\section{White matter changes}

Among the functional neuroimaging modalities, DTI is an advanced and non-invasive MRI technique that is sensitive to the cerebral WM architecture of the human brain, providing valuable information about the integrity and fiber orientation of the WM tracts in vivo. The most widely used parameters derived from DTI are fractional anisotropy (FA) and mean diffusivity (MD), both of which can provide complementary information on subtle abnormalities of the WM microstructure in diverse neurologic and psychiatric disorders. ${ }^{7}$ Decreased FA reflects a reduced microstructural integrity within the WM tracts, and factors influencing FA include membrane and myelin integrity and fiber density. ${ }^{94} \mathrm{MD}$ increases with microscopic barrier disruption and extracellular fluid accumulation; therefore, increased $M D$ is encountered in various pathologic conditions that accompany tissue degeneration and edema. ${ }^{95}$ There is robust pathologic evidence that FA and MD are directly affected by the myelin content of WM and, to a lesser degree, by axonal count in postmortem brains of multiple sclerosis. ${ }^{96}$

There are 10 studies published in English that evaluated WM integrity in JME using diverse analytic methods of DTI (Table 4). .10,21,22,41,58,97-99 $^{-1}$ Using a whole-brain voxel-wise manner implemented in statistical parametric mapping (SPM; http://wwww.il.ion.ucl.ac.uk/spm/), Deppe et al. ${ }^{8}$ first reported significant FA reductions in WM regions associated with the anterior thalamus and prefrontal cortex in a patient group, indicating that JME is associated with WM abnormalities of the thalamofrontal network. A subsequent study by the same group employed a region of interest approach and detected FA reductions in the thalamocortical and frontal WM tracts, corroborating their former findings. ${ }^{9}$ Tract-based spatial statistics (TBSS; https://fsl.fmrib.ox.ac.uk/fsl/fslwi$\mathrm{ki} /$ TBSS) is a novel analytic tool of DTI datasets that provides an observer-independent, automated whole-brain voxel-wise analysis of FA and MD without the need for restriction to a priori brain regions. ${ }^{100,101}$ It can circumvent the problems of cross-subject image registration and random selection of spatial smoothing factors in voxel-based DTI analysis incorporated into SPM by making use of the intrinsic anisotropic property of WM and projecting the FA values of the tracts onto a virtual skeleton that runs through the median part of the tract. TBSS, therefore, reliably improves sensitivity, objectivity, and interpretability of voxel-wise comparisons of the microstructural WM integrity between groups of subjects. ${ }^{100,101}$ Indeed, TBSS is more sensitive than the SPM method in detecting WM abnormalities in patients with mesial temporal lobe epilepsy. ${ }^{102}$ Combining VBM and
TBSS, O'Muircheartaigh et al. showed GM volume reductions in the supplementary motor area and posterior cingulate cortex and FA reductions in underlying WM of the corpus callosum in patient group, implicating focal cortical regions and their connecting WM tracts in JME. ${ }^{21}$ Another study using TBSS demonstrated FA reductions and MD increases in bilateral anterior and superior corona radiata, genu and body of the corpus callosum, and multiple frontal WM tracts as well as frontal executive dysfunctions, highlighting a pivotal role of frontal lobe WM abnormality in the pathogenesis and frontal cognitive impairment of JME. ${ }^{10}$ Other DTI studies using either a region of interest or whole-brain voxel-wise approach replicated the findings of disrupted microstructural integrity (reduced FA and increased MD) of the WM tracts, particularly the corpus callosum and frontal WM tracts, emphasizing widespread WM abnormalities in the pathogenetic process that underlies JME. $22,58,98,99$

DTI probabilistic tractography is a valuable, non-invasive tool that can visualize and characterize the WM tracts and quantify the structural connectivity between the seed regions within the various brain networks. ${ }^{103}$ Using this probabilistic tractography, Vulliemoz et al. disclosed a reduction in the structural connectivity of the supplementary motor area as revealed by reduced FA and increased MD in JME patients relative to controls and in patients with frontal lobe epilepsy. ${ }^{97}$ Another study found reduced structural connectivity between the supplementary motor area and anterior thalamus, providing convincing evidence for a specific thalamocortical network dysfunction in JME. ${ }^{41}$

\section{Conclusions}

Given the typical EEG features of generalized spike-wave discharges and no visible focal lesions on clinical MR images, JME has been traditionally recognized as a form of generalized epilepsy. However, recent advances in sensitive neuroimaging techniques provide qualitative and quantitative methods of unveiling the underlying pathophysiological mechanisms involved in JME. Specifically, computational analyses of multimodal MRIs have disclosed focal or regional abnormalities of the brain, particularly in the thalamus and frontal cortex, and thalamocortical network abnormality in JME patients. Converging evidence from a large number of multimodal MRI studies has supported the notion that JME may not be a 'generalized' epilepsy, but a 'network' epilepsy involving specific subcortical and cortical regions, especially in the thalamofrontal network. This concept of thalamofrontal network epilepsy could provide an explanatory 
framework for the specific neuroimaging findings, seizure type, and seizure-provoking mechanisms, and implicate personality disorders and frontal cognitive dysfunctions in JME.

\section{References}

1. Camfield CS, Striano P, Camfield PR. Epidemiology of juvenile myoclonic epilepsy. Epilepsy Behav 2013;28 Suppl 1:S15-7.

2. Blumenfeld $H$. Cellular and network mechanisms of spike-wave seizures. Epilepsia 2005;46 Suppl 9:21-33.

3. Proposal for revised classification of epilepsies and epileptic syndromes. Commission on Classification and Terminology of the International League Against Epilepsy. Epilepsia 1989;30:389-99.

4. Anderson J, Hamandi K. Understanding juvenile myoclonic epilepsy: contributions from neuroimaging. Epilepsy Res 2011;94:127-37.

5. Seneviratne U, Cook M, D'Souza W. Focal abnormalities in idiopathic generalized epilepsy: a critical review of the literature. Epilepsia 2014;55:1157-69.

6. Koepp MJ, Woermann F, Savic I, Wandschneider B. Juvenile myoclonic epilepsy--neuroimaging findings. Epilepsy Behav 2013;28 Suppl 1:S40-4.

7. Le Bihan D, Mangin JF, Poupon $C$, et al. Diffusion tensor imaging: concepts and applications. J Magn Reson Imaging 2001;13:534-46.

8. Deppe $M$, Kellinghaus $C$, Duning $T$, et al. Nerve fiber impairment of anterior thalamocortical circuitry in juvenile myoclonic epilepsy. Neurology 2008;71:1981-5.

9. Keller SS, Ahrens T, Mohammadi S, et al. Microstructural and volumetric abnormalities of the putamen in juvenile myoclonic epilepsy. Epilepsia 2011;52:1715-24.

10. Kim JH, Suh SI, Park SY, et al. Microstructural white matter abnormality and frontal cognitive dysfunctions in juvenile myoclonic epilepsy. Epilepsia 2012;53:1371-8.

11. von Podewils $F$, Runge $U$, Krüger $S$, et al. Diffusion tensor imaging abnormalities in photosensitive juvenile myoclonic epilepsy. Eur J Neurol 2015;22:1192-200.

12. Ashburner J, Friston KJ. Voxel-based morphometry--the methods. Neuroimage 2000;11(6 Pt 1):805-21.

13. Woermann FG, Free SL, Koepp MJ, Sisodiya SM, Duncan JS. Abnormal cerebral structure in juvenile myoclonic epilepsy demonstrated with voxel-based analysis of MRI. Brain 1999;122(Pt 11):2101-8.

14. Betting $L E$, Mory $S B$, Li $L M$, et al. Voxel-based morphometry in patients with idiopathic generalized epilepsies. Neuroimage 2006:32:498-502.

15. Tae WS, Hong SB, Joo EY, et al. Structural brain abnormalities in juvenile myoclonic epilepsy patients: volumetry and voxel-based morphometry. Korean J Radiol 2006;7:162-72.

16. Kim JH, Lee JK, Koh SB, et al. Regional grey matter abnormalities in juvenile myoclonic epilepsy: a voxel-based morphometry study. Neuroimage 2007;37:1132-7.

17. Lin $\mathrm{K}$, Jackowski AP, Carrete $\mathrm{H}$ Jr, et al. Voxel-based morphometry evaluation of patients with photosensitive juvenile myoclonic epilepsy. Epilepsy Res 2009;86:138-45.

18. Roebling R, Scheerer N, Uttner I, Gruber O, Kraft E, Lerche $H$. Evaluation of cognition, structural, and functional MRI in juvenile myoclonic epilepsy. Epilepsia 2009;50:2456-65.

19. de Araújo Filho GM, Jackowski AP, Lin K, et al. Personality traits related to juvenile myoclonic epilepsy: MRI reveals prefrontal abnormalities through a voxel-based morphometry study. Epilepsy Behav 2009;15:202-7.

20. Mory SB, Betting LE, Fernandes PT, et al. Structural abnormalities of the thalamus in juvenile myoclonic epilepsy. Epilepsy Behav 2011;21:407-11.

21. O'Muircheartaigh J, Vollmar C, Barker GJ, et al. Focal structural changes and cognitive dysfunction in juvenile myoclonic epilepsy. Neurology 2011;76:34-40.

22. Liu M, Concha L, Beaulieu C, Gross DW. Distinct white matter abnormalities in different idiopathic generalized epilepsy syndromes. Epilepsia 2011;52:2267-75.

23. Kim JH, Kim JB, Seo WK, Suh SI, Koh SB. Volumetric and shape analysis of thalamus in idiopathic generalized epilepsy. I Neurol 2013; 260:1846-54.

24. Swartz BE, Spitz J, Vu AL, Mandelkern M, Su ML. Heterogeneity of anatomic regions by MR volumetry in juvenile myoclonic epilepsy. Acta Neurol Scand 2016;134:300-8.

25. Meencke HJ, Janz D. Neuropathological findings in primary generalized epilepsy: a study of eight cases. Epilepsia 1984;25:8-21.

26. Meencke HJ. Neuron density in the molecular layer of the frontal cortex in primary generalized epilepsy. Epilepsia 1985;26:450-4.

27. Lyon G, Gastaut H. Considerations on the significance attributed to unusual cerebral histological findings recently described in eight patients with primary generalized epilepsy. Epilepsia 1985;26:365-7.

28. Opeskin K, Kalnins RM, Halliday G, Cartwright H, Berkovic SF. Idiopathic generalized epilepsy: lack of significant microdysgenesis. Neurology 2000;55:1101-6.

29. Swartz $B E$, Simpkins $F$, Halgren $E$, et al. Visual working memory in primary generalized epilepsy: an 18FDG-PET study. Neurology 1996; 47:1203-12.

30. Simister RJ, McLean MA, Barker GJ, Duncan JS. Proton MRS reveals frontal lobe metabolite abnormalities in idiopathic generalized epilepsy. Neurology 2003;61:897-902.

31. Savic I, Osterman Y, Helms G. MRS shows syndrome differentiated metabolite changes in human-generalized epilepsies. Neuroimage 2004;21:163-72.

32. Lin K, Carrete H Jr, Lin J, et al. Magnetic resonance spectroscopy reveals an epileptic network in juvenile myoclonic epilepsy. Epilepsia 2009:50:1191-200.

33. Hattingen $E$, Lückerath $C$, Pellikan $S$, et al. Frontal and thalamic changes of GABA concentration indicate dysfunction of thalamofrontal networks in juvenile myoclonic epilepsy. Epilepsia 2014;55:1030-7. 
34. Zhang L, Li H, Hong P, Zou X. Proton magnetic resonance spectroscopy in juvenile myoclonic epilepsy: a systematic review and meta-analysis. Epilepsy Res 2016;121:33-8.

35. McGill ML, Devinsky O, Kelly C, et al. Default mode network abnormalities in idiopathic generalized epilepsy. Epilepsy Behav 2012;23:353-9.

36. Kim JB, Suh SI, Seo WK, Oh K, Koh SB, Kim JH. Altered thalamocortical functional connectivity in idiopathic generalized epilepsy. Epilepsia 2014;55:592-600.

37. Devinsky O, Gershengorn J, Brown E, Perrine K, Vazquez B, Luciano D. Frontal functions in juvenile myoclonic epilepsy. Neuropsychiatry Neuropsychol Behav Neurol 1997;10:243-6.

38. Elger CE, Helmstaedter C, Kurthen M. Chronic epilepsy and cognition. Lancet Neurol 2004;3:663-72.

39. Piazzini A, Turner K, Vignoli A, Canger R, Canevini MP. Frontal cognitive dysfunction in juvenile myoclonic epilepsy. Epilepsia 2008;49: 657-62.

40. Pulsipher DT, Seidenberg M, Guidotti L, et al. Thalamofrontal circuitry and executive dysfunction in recent-onset juvenile myoclonic epilepsy. Epilepsia 2009;50:1210-9.

41. O'Muircheartaigh J, Vollmar C, Barker GJ, et al. Abnormal thalamocortical structural and functional connectivity in juvenile myoclonic epilepsy. Brain 2012;135(Pt 12):3635-44.

42. Wandschneider B, Thompson PJ, Vollmar C, Koepp MJ. Frontal lobe function and structure in juvenile myoclonic epilepsy: a comprehensive review of neuropsychological and imaging data. Epilepsia 2012;53: 2091-8.

43. Ridgway GR, Henley SM, Rohrer JD, Scahill Rl, Warren JD, Fox NC. Ten simple rules for reporting voxel-based morphometry studies. Neuroimage 2008;40:1429-35.

44. Pell GS, Briellmann RS, Chan $C H$, Pardoe $H$, Abbott DF, Jackson GD. Selection of the control group for VBM analysis: influence of covariates, matching and sample size. Neuroimage 2008;41:1324-35.

45. Barnes J, Ridgway GR, Bartlett J, et al. Head size, age and gender adjustment in MRI studies: a necessary nuisance? Neuroimage 2010:53:1244-55.

46. Peelle JE, Cusack R, Henson RN. Adjusting for global effects in voxel-based morphometry: gray matter decline in normal aging. Neuroimage 2012;60:1503-16.

47. Ioannidis JP. Excess significance bias in the literature on brain volume abnormalities. Arch Gen Psychiatry 2011;68:773-80.

48. Radua J, Mataix-Cols D, Phillips ML, et al. A new meta-analytic method for neuroimaging studies that combines reported peak coordinates and statistical parametric maps. Eur Psychiatry 2012;27:605-11.

49. Cao B, Tang Y, Li J, Zhang X, Shang HF, Zhou D. A meta-analysis of voxel-based morphometry studies on gray matter volume alteration in juvenile myoclonic epilepsy. Epilepsy Res 2013;106:370-7.

50. Fischl B, Dale AM. Measuring the thickness of the human cerebral cortex from magnetic resonance images. Proc Natl Acad Sci U S A 2000;97:11050-5.
51. Han X, Jovicich J, Salat $D$, et al. Reliability of MRI-derived measurements of human cerebral cortical thickness: the effects of field strength, scanner upgrade and manufacturer. Neuroimage 2006;32:180-94.

52. Acosta O, Bourgeat P, Zuluaga MA, et al. Automated voxel-based 3D cortical thickness measurement in a combined Lagrangian-Eulerian PDE approach using partial volume maps. Med Image Anal 2009;13: 730-43.

53. Winkler AM, Kochunov P, Blangero J, et al. Cortical thickness or grey matter volume? The importance of selecting the phenotype for imaging genetics studies. Neuroimage 2010;53:1135-46.

54. Tae WS, Kim SH, Joo EY, et al. Cortical thickness abnormality in juvenile myoclonic epilepsy. J Neurol 2008;255:561-6.

55. Ronan L, Alhusaini S, Scanlon C, Doherty CP, Delanty N, Fitzsimons $M$. Widespread cortical morphologic changes in juvenile myoclonic epilepsy: evidence from structural MRI. Epilepsia 2012;53:651-8.

56. Alhusaini S, Ronan L, Scanlon C, et al. Regional increase of cerebral cortex thickness in juvenile myoclonic epilepsy. Epilepsia 2013;54: e138-41.

57. Lin JJ, Dabbs K, Riley JD, et al. Neurodevelopment in new-onset juvenile myoclonic epilepsy over the first 2 years. Ann Neurol 2014;76:660-8.

58. Kim SH, Lim SC, Kim W, et al. Extrafrontal structural changes in juvenile myoclonic epilepsy: a topographic analysis of combined structural and microstructural brain imaging. Seizure 2015;30:124-31.

59. Park KM, Kim TH, Han YH, et al. Brain morphology in juvenile myoclonic epilepsy and absence seizures. Acta Neurol Scand 2016;133: 111-8.

60. Keller SS, Gerdes JS, Mohammadi S, et al. Volume estimation of the thalamus using freesurfer and stereology: consistency between methods. Neuroinformatics 2012;10:341-50.

61. Saini J, Sinha S, Bagepally BS, et al. Subcortical structural abnormalities in juvenile myoclonic epilepsy (JME): MR volumetry and vertex based analysis. Seizure 2013;22:230-5.

62. Helms G, Ciumas C, Kyaga S, Savic I. Increased thalamus levels of glutamate and glutamine $(\mathrm{G} \mid \mathrm{x})$ in patients with idiopathic generalised epilepsy. I Neurol Neurosurg Psychiatry 2006;77:489-94.

63. Kim JH, Im KC, Kim JS, Lee SA, Kang JK. Correlation of interictal spike-wave with thalamic glucose metabolism in juvenile myoclonic epilepsy. Neuroreport 2005;16:1151-5.

64. Bernasconi A, Bernasconi N, Natsume J, Antel SB, Andermann F, Arnold $\mathrm{DL}$. Magnetic resonance spectroscopy and imaging of the thalamus in idiopathic generalized epilepsy. Brain 2003;126(Pt 11):2447-54.

65. Gotman J, Grova C, Bagshaw A, Kobayashi E, Aghakhani Y, Dubeau F. Generalized epileptic discharges show thalamocortical activation and suspension of the default state of the brain. Proc Natl Acad Sci U S A 2005;102:15236-40.

66. Tyvaert L, Chassagnon S, Sadikot A, LeVan P, Dubeau F, Gotman J. Thalamic nuclei activity in idiopathic generalized epilepsy: an EEG-fMRI study. Neurology 2009;73:2018-22. 
67. Pugnaghi M, Carmichael DW, Vaudano AE, et al. Generalized spike and waves: effect of discharge duration on brain networks as revealed by BOLD fMRI. Brain Topogr 2014;27:123-37.

68. Ji GJ, Zhang Z, Xu Q, et al. Identifying corticothalamic network epicenters in patients with idiopathic generalized epilepsy. AJNR Am J Neuroradiol 2015;36:1494-500.

69. Brevard ME, Kulkarni P, King JA, Ferris CF. Imaging the neural substrates involved in the genesis of pentylenetetrazol-induced seizures. Epilepsia 2006;47:745-54.

70. Mirski MA, Tsai YC, Rossell LA, Thakor NV, Sherman DL. Anterior thalamic mediation of experimental seizures: selective EEG spectral coherence. Epilepsia 2003;44:355-65.

71. Banerjee PK, Snead OC 3rd. Thalamic mediodorsal and intralaminar nuclear lesions disrupt the generation of experimentally induced generalized absence-like seizures in rats. Epilepsy Res 1994;17:193-205.

72. Aghakhani $Y$, Bagshaw AP, Bénar $C G$, et al. fMRI activation during spike and wave discharges in idiopathic generalized epilepsy. Brain 2004;127(Pt 5):1127-44.

73. Carney PW, Masterton RA, Harvey AS, Scheffer IE, Berkovic SF, Jackson GD. The core network in absence epilepsy. Differences in cortical and thalamic BOLD response. Neurology 2010;75:904-11.

74. Moeller $F$, Siebner HR, Wolff $S$, et al. Changes in activity of striato-thalamo-cortical network precede generalized spike wave discharges. Neuroimage 2008;39:1839-49.

75. Behrens TE, Johansen-Berg $H$, Woolrich MW, et al. Non-invasive mapping of connections between human thalamus and cortex using diffusion imaging. Nat Neurosci 2003;6:750-7.

76. Johansen-Berg $H$, Behrens $T E$, Sillery $E$, et al. Functional-anatomical validation and individual variation of diffusion tractography-based segmentation of the human thalamus. Cereb Cortex 2005;15:31-9.

77. Zhang D, Snyder AZ, Shimony JS, Fox MD, Raichle ME. Noninvasive functional and structural connectivity mapping of the human thalamocortical system. Cereb Cortex 2010;20:1187-94.

78. Patenaude B, Smith SM, Kennedy DN, Jenkinson M. A Bayesian model of shape and appearance for subcortical brain segmentation. Neuroimage 2011;56:907-22.

79. Ciumas C, Wahlin TB, Jucaite A, Lindstrom P, Halldin C, Savic I. Reduced dopamine transporter binding in patients with juvenile myoclonic epilepsy. Neurology 2008;71:788-94.

80. Deransart C, Vercueil L, Marescaux C, Depaulis A. The role of basal ganglia in the control of generalized absence seizures. Epilepsy Res 1998;32:213-23.

81. Deransart C, Riban V, Lê B, Marescaux C, Depaulis A. Dopamine in the striatum modulates seizures in a genetic model of absence epilepsy in the rat. Neuroscience 2000;100:335-44.

82. Slaght SJ, Paz T, Chavez M, Deniau JM, Mahon S, Charpier S. On the activity of the corticostriatal networks during spike-and-wave discharges in a genetic model of absence epilepsy. J Neurosci 2004;24: 6816-25.
83. Hamandi K, Salek-Haddadi A, Laufs $H$, et al. EEG-fMRI of idiopathic and secondarily generalized epilepsies. Neuroimage 2006;31:1700-10.

84. Li Q, Luo C, Yang T, et al. EEG-fMRI study on the interictal and ictal generalized spike-wave discharges in patients with childhood absence epilepsy. Epilepsy Res 2009;87:160-8.

85. Luo C, Li Q, Xia Y, et al. Resting state basal ganglia network in idiopathic generalized epilepsy. Hum Brain Mapp 2012;33:1279-94.

86. Alexander GE, Crutcher MD. Functional architecture of basal ganglia circuits: neural substrates of parallel processing. Trends Neurosci 1990;13:266-71.

87. Landvogt C, Buchholz HG, Bernedo V, Schreckenberger M, Werhahn $\mathrm{KJ}$. Alteration of dopamine D2/D3 receptor binding in patients with juvenile myoclonic epilepsy. Epilepsia 2010;51:1699-706.

88. Yang $T$, Fang Z, Ren J, et al. Altered spontaneous activity in treatment-naive childhood absence epilepsy revealed by Regional Homogeneity. J Neurol Sci 2014;340:58-62.

89. Lin K, de Araujo Filho GM, Pascalicchio TF, et al. Hippocampal atrophy and memory dysfunction in patients with juvenile myoclonic epilepsy. Epilepsy Behav 2013;29:247-51.

90. Ristić AJ, Ostojić J, Kozić D, et al. Hippocampal metabolic dysfunction in juvenile myoclonic epilepsy: 3D multivoxel spectroscopy study. J Neurol Sci 2011;305:139-42.

91. Holmes MD, Quiring J, Tucker DM. Evidence that juvenile myoclonic epilepsy is a disorder of frontotemporal corticothalamic networks. Neuroimage 2010;49:80-93.

92. Pascalicchio TF, de Araujo Filho GM, da Silva Noffs $M H$, et al. Neuropsychological profile of patients with juvenile myoclonic epilepsy: a controlled study of 50 patients. Epilepsy Behav 2007;10:263-7.

93. Sonmez F, Atakli D, Sari H, Atay T, Arpaci B. Cognitive function in juvenile myoclonic epilepsy. Epilepsy Behav 2004;5:329-36.

94. Beaulieu C. The basis of anisotropic water diffusion in the nervous system - a technical review. NMR Biomed 2002;15:435-55.

95. Assaf Y. Can we use diffusion MRI as a bio-marker of neurodegenerative processes? Bioessays 2008;30:1235-45.

96. Schmierer K, Wheeler-Kingshott CA, Boulby PA, et al. Diffusion tensor imaging of post mortem multiple sclerosis brain. Neuroimage 2007; 35:467-77.

97. Vulliemoz S, Vollmar C, Koepp MJ, et al. Connectivity of the supplementary motor area in juvenile myoclonic epilepsy and frontal lobe epilepsy. Epilepsia 2011;52:507-14.

98. Focke NK, Diederich C, Helms G, Nitsche MA, Lerche H, Paulus W. Idiopathic-generalized epilepsy shows profound white matter diffusion-tensor imaging alterations. Hum Brain Mapp 2014;35:3332-42.

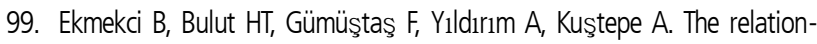
ship between white matter abnormalities and cognitive functions in new-onset juvenile myoclonic epilepsy. Epilepsy Behav 2016;62:166-70.

100. Smith SM, Jenkinson M, Johansen-Berg $H$, et al. Tract-based spatial statistics: voxelwise analysis of multi-subject diffusion data. Neuroimage 2006;31:1487-505. 
101. Smith SM, Johansen-Berg $H$, Jenkinson $M$, et al. Acquisition and voxelwise analysis of multi-subject diffusion data with tract-based spatial statistics. Nat Protoc 2007;2:499-503.

102. Focke NK, Yogarajah M, Bonelli SB, Bartlett PA, Symms MR, Duncan JS. Voxel-based diffusion tensor imaging in patients with mesial tem- poral lobe epilepsy and hippocampal sclerosis. Neuroimage 2008;40: 728-37.

103. Johansen-Berg $H$, Rushworth MF. Using diffusion imaging to study human connectional anatomy. Annu Rev Neurosci 2009;32:75-94. 